\title{
Avaliação das condições de conforto visual em edificação tombada com novo uso: estudo de caso do Casarão 2, Pelotas/RS
}

\author{
ESTIMA SILVA, Mariana ${ }^{1}$ \\ VIANNA, Saionara ${ }^{2}$ \\ MEDVEDOVSKY, Nirce ${ }^{3}$ \\ TORRES, Ariela S. ${ }^{4}$ \\ SALAMONI, Isabel ${ }^{5}$
}

\begin{abstract}
1PROGRAU, Universidade Federal de Pelotas, Pelotas, Brasil. estimasilva.m@gmail.com 2 PROGRAU, Universidade Federal de Pelotas, Pelotas, Brasil. svianna75@hotmail.com 3 PROGRAU, Universidade Federal de Pelotas, Pelotas, Brasil. nirce.sul@gmail.com 4 PROGRAU, Universidade Federal de Pelotas, Pelotas, Brasil. arielatorres@gmail.com 5 PROGRAU, Universidade Federal de Pelotas, Pelotas, Brasil. isalamoni@gmail.com
\end{abstract}

\section{Resumo}

Estudos referentes à utilização de edificações históricas por novos usos são muito relevantes atualmente, visto que tratam de temas como economia de matéria-prima e conservação de legados culturais. O processo de retrofit resume-se em ações de restauro com inserção de um novo uso ao prédio. Este trabalho teve como objetivo analisar se as condições de conforto lumínico são satisfatórias em ambientes de uma edificação tombada, que passou por retrofit, em relação a seu novo uso, o de escritórios. A fim de alcançar o objetivo da pesquisa, foram escolhidos dois ambientes para estudo, com base em técnicas de walkthrough e levantamento de arquivo. Nesses ambientes foram realizadas medições lumínicas com luxímetros e aplicação de questionários com os usuários. A partir dos métodos quantitativos e qualitativos de pesquisa foi possível alcançar e comparar os resultados, que verificaram a não observância das condições de conforto lumínico durante maior parte do dia. Sendo assim, é possível dizer que para estes ambientes, o novo uso não satisfaz as condições de conforto visual dos usuários, ou seja, o processo de retrofit não atingiu seus objetivos por completo. Também é possível afirmar que o processo de conservação visou apenas a manutenção das características construtivas nestes ambientes.

Palavras-Chave: Novos usos; Conforto lumínico; Usuários.

\begin{abstract}
Studies on the use of historic buildings for new uses are very relevant today, since it deals with topics such as saving raw materials and the conservation of cultural legacies. The retrofit process can be summarized in restoration actions with insertion of a new use of the building. This study aims to examine whether the luminal comfort conditions are satisfactory in environments of a historical building, which underwent retrofit, with respect to its new use. In order to achieve the objective of the research, were chosen two environments for study, based on 'walkthrough' techniques and file survey. In these environments were carried measurements and questionnaires with users. From the quantitative and qualitative research methods it was possible to achieve and compare the results, found that don't exist the basic visual comfort conditions during most of the day. Thus, one can say that for these environments, the new use didn't meet the visual comfort conditions for users, ie, the process of retrofitting has not achieved its objectives in full. Can also say that the conservation process aimed at preserving the construction in these environments.
\end{abstract}

Key-Words: New uses; Luminic confort; users. 


\section{Introdução e Fundamentação Teórica}

O conceito de preservação é bastante complexo, podendo ser definido como o conjunto de medidas que buscam a conservação da cultura de uma sociedade (RABELLO, 2009). A conservação pode estar associada a diferentes bens culturais de um povo, porém, para Choay (2001), a arquitetura é o patrimônio cultural que possui relação mais estreita com a população, tornando tão importante sua preservação. Dentre as diversas maneiras de se efetuar a preservação de uma edificação, estão o tombamento e o inventário. Ambas são medidas jurídicas que restringem a propriedade do dono sobre a edificação (MEIRA, 2008).

No inventário, um conjunto de edificações, importantes para seu contexto e entorno, é catalogado, a fim de que suas características de fachada pública e volumetria sejam mantidas em harmonia. O tombamento restringe ainda mais o poder do proprietário, visto que a edificação não poderá sofrer nenhuma alteração, externa e internamente, sem a autorização do órgão responsável (SECRETARIA MUNICIPAL DE CULTURA, 2008).

Sabe-se que toda edificação possui um tempo de vida útil, o que não é diferente quando se trata de edificações com valor histórico, e, mantê-las em uso, é a melhor forma de garantir a continuidade de sua vida. Contudo, é visível que os usos a que foram destinadas as edificações, muitas vezes, não são mais compatíveis com as necessidades da sociedade no contexto em que estão inseridas. Sendo assim, a modificação de uso torna-se uma alternativa de preservação (AYKAL et al, 2011).

O processo de retrofit garante a prédios históricos a manutenção de seu uso, porém com uma nova finalidade, gerando neles um novo ciclo (MEIRA, 2008). Segundo a International Energy Agency (2000), muitos imóveis passam por esse processo por apresentarem um mau estado de conservação e pela necessidade de um novo layout em seu interior.

No entanto, a definição do novo uso para uma edificação histórica é uma decisão complexa, visto que deve ser capaz de garantir a sobrevivência do prédio. Heidtmann (2007), que realizou uma análise de novos usos para prédios históricos na cidade de Pelotas/RS, afirma que a decisão do novo uso é, além de uma possibilidade, um problema de arquitetura, já que questões relacionadas a estratégias de preservação dos aspectos culturais e históricos precisam ser consideradas, bem como recuperação de características construtivas e estruturais.

Um estudo do estado de conservação do Casarão 2, na cidade de Pelotas/RS, relacionado à presença de biodeterioração, realizado por Guerra (2006), concluiu que o uso ao qual a edificação será destinada deve referenciar-se ao potencial da mesma, com o único intuito de lhe agregar valor e garantir sua conservação.

Um ponto importante a se considerar, tanto em edificações que sofreram retrofit, quanto em qualquer edificação, é o conforto dos usuários. A iluminação é um dos aspectos de conforto ambiental que sempre fez parte dos projetos arquitetônicos ao longo da história, visto que possui duas funções básicas, a de transmitir a "atmosfera" desejada nos ambientes internos, e a de torná-los funcionais. Pensar o modo como a iluminação natural será tratada é um ponto essencial em qualquer processo de retrofit (INTERNATIONAL ENERGY AGENCY, 2000; AYKAL et al, 2011).

A janela, por ser a responsável pela incidência da luz natural no interior das edificações, principalmente em tempos de inexistência da energia elétrica, é o símbolo principal da iluminação na arquitetura. Sendo assim, as janelas e o modo como se iluminava os cômodos, foram evoluindo ao longo dos anos, juntamente com os materiais e técnicas construtivas. As fachadas de edificações do século XIX são caracterizadas por uma maior presença de vazios que cheios, quando comparadas à edificações anteriores, demonstrando a preocupação com a entrada de luz natural (GONÇALVES et al, 2011).

No entanto, hoje sabe-se que a quantidade de luz não é o fundamental em uma edificação, e sim sua qualidade. A iluminação garante a visualização do ambiente, a movimentação com segurança e a realização de tarefas com eficiência de acordo com o uso a que é destinado cada ambiente (NBR 8995- 
1, 2013). Quando um projeto arquitetônico prevê condições de conforto ambiental, seja lumínico, térmico ou acústico, está colocando o usuário em primeiro lugar na edificação (GONÇALVES et al, 2011).

A cidade de Pelotas, possui um grande exemplar de edificações históricas, que mesclam influências de diversas nacionalidades, como a portuguesa, a italiana e a alemã. Atualmente, existem 19 imóveis tombados, municipal, estadual e nacionalmente, incluindo prédios e monumentos. Bem como mais de 1.700 prédios inventariados pelo município. Pelo fato de a cidade ter atingido seu auge econômico no século XIX, quando destacava-se na produção do charque, as construções dessa época possuem grande importância para a história da sociedade (SECRETARIA MUNICIPAL DE CULTURA, 2008).

Baseado nesse referencial, o presente trabalho objetiva analisar se a edificação em estudo, o Casarão 2, que sofreu processo de retrofit, está satisfazendo as condições de conforto lumínico para seu novo uso, ou, se o processo visou apenas a manutenção das características formais do prédio.

\section{Metodologia}

Esta pesquisa foi desenvolvida em cinco etapas principais, estando estas listadas abaixo.

\subsection{Caracterização do objeto de estudo}

O Casarão 2, localizado na Praça Coronel Pedro Osório, no 02 , conforme Figura 1, foi construído no ano de 1830, como residência do charqueador José Vieira Vianna. Seu estilo original é o colonial, no entanto, em 1880, o prédio sofreu reforma, passando a exibir o estilo eclético, visível até hoje. No ano da reforma, um mirante foi construído no terceiro pavimento, de onde era possível observar o movimento no Canal São Gonçalo. A edificação possui tipologia em "U”, com implantação de esquina, possuindo janelas para as orientações Norte, Sul, Leste e Oeste, sendo a última orientação a da fachada principal (KNOP, 2012).

No ano de 1977 o Casarão 2 foi tombado pelo IPHAN, sofrendo diversos processos pontuais de restauro. Apenas em 2000, com o Programa Monumenta, o prédio foi totalmente restaurado e entregue à população em 2004, abrigando dois novos usos. Desde então, o Centro Cultural Adail Bento Costa situa-se no pavimento térreo, e a Secretaria Municipal de Cultura, no segundo pavimento (KNOP, 2012).

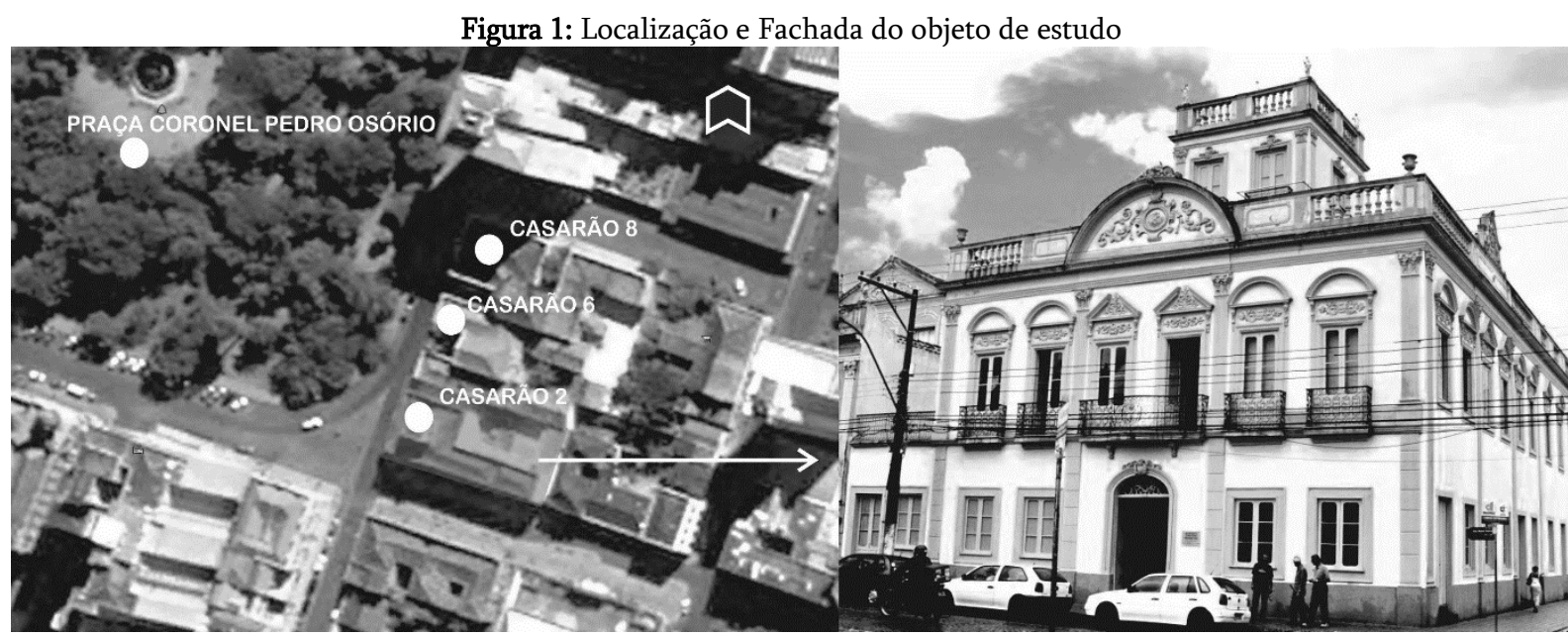

Fonte: Adaptação de Google Earth (2015)

\subsection{Levantamento de arquivo}

Esta etapa é considerada o ponto de partida do estudo. Nela foi realizado o levantamento dos arquivos, cedidos pela Secretaria Municipal de Cultura de Pelotas, relacionados aos levantamentos da edificação antes do processo de restauro, bem como o projeto de restauro do Casarão 2. Além disso, dissertações que utilizaram a mesma edificação para outros estudos também serviram como base para o levantamento de arquivo. 


\subsection{Walkthrough}

Segundo Rheingantz et al (2009), o walkthrough é um método, muito utilizado na avaliação do ambiente construído, que mescla a observação, feita em percurso, com entrevistas. A partir desse processo é possível analisar os usos dos ambientes e seus aspectos positivos e negativos. Esta etapa foi realizada em um dia do mês de setembro de 2015, no período da tarde. Utilizando-se das plantas baixas da edificação, foram realizadas anotações a partir de levantamento visual e por meio de entrevistas com funcionários. Também foi realizado o levantamento fotográfico dos ambientes.

A partir dessa etapa foi possível escolher os ambientes para realizar as medições, Figura 2. As salas escolhidas seguiram o critério de maior número de funcionários e diferentes orientações solares em um mesmo ambiente. São dois ambientes localizados no 2o pavimento do prédio, com orientações solares norte, oeste e sul.
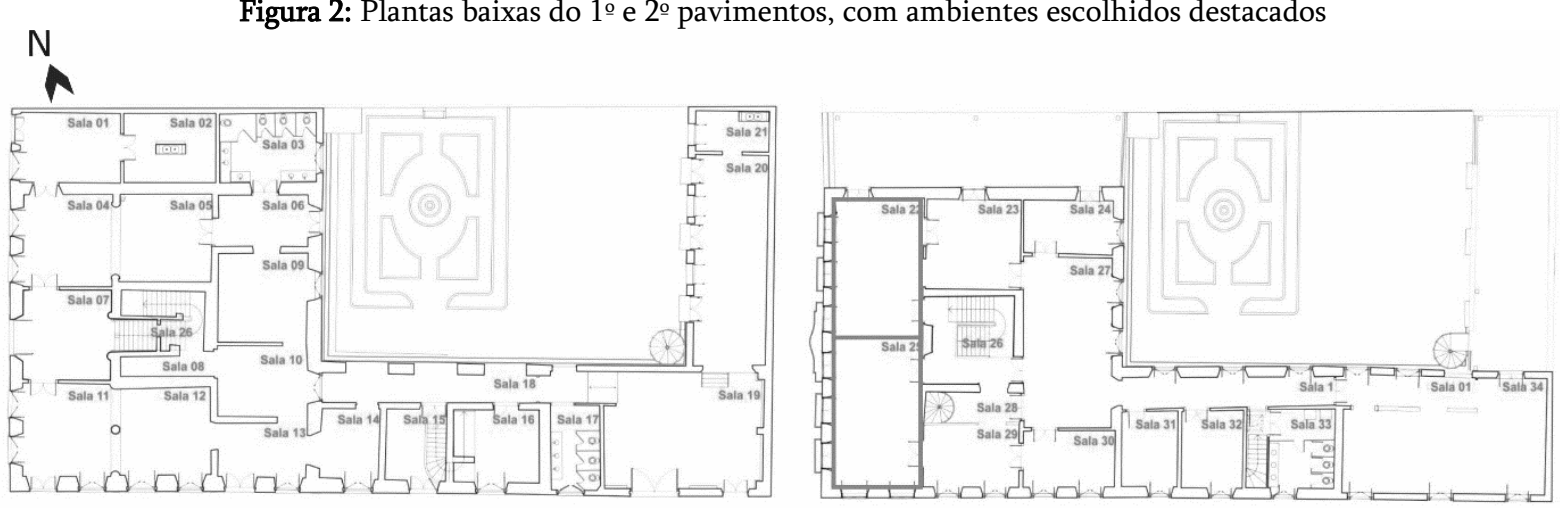

Fonte: Adaptação de Knop (2012)

\subsection{Medições lumínicas}

As medições das variáveis físicas ambientais de conforto lumínico foram realizadas de acordo com a NBR 15.215-4 (ABNT, 2005). A disposição e quantidade de sensores foi calculada a partir de equação estipulada na norma, resultando em 16 pontos em cada ambiente, como mostra a Figura 3. Nos pontos de medição, o luxímetro foi colocado à uma distância de $75 \mathrm{~cm}$ do piso. Também foi estipulado um ponto externo, distante $55 \mathrm{~cm}$ do prédio, seguindo o critério de fachada com maior número de aberturas, a fim de realizar o cálculo de Contribuição de Iluminação Natural.

Os dois ambientes foram levantados por duas pessoas durante um dia, 9 de setembro de 2015.
Foram realizadas medições das condições lumínicas no período das 9 horas às 17 horas, com medições instantâneas a cada 2 horas. Em uma primeira etapa, os ambientes foram medidos apenas com o uso da iluminação natural. Em uma segunda etapa de medições, a iluminação artificial também foi considerada. Considerou-se a condição de céu normal para o mês de setembro, claro com períodos encobertos.

Foram utilizados luxímetros Instrutherm LD-209, cedidos pelo Laboratório de Materiais da Faculdade de Arquitetura e Urbanismo da UFPel. As medições foram realizadas nas condições habituais de trabalho dos usuários, ou seja, com janelas abertas e/ou fechadas de acordo com a necessidade dos mesmos. 
Figura 3: Marcações para medições com luxímetros

$\mathrm{N}$

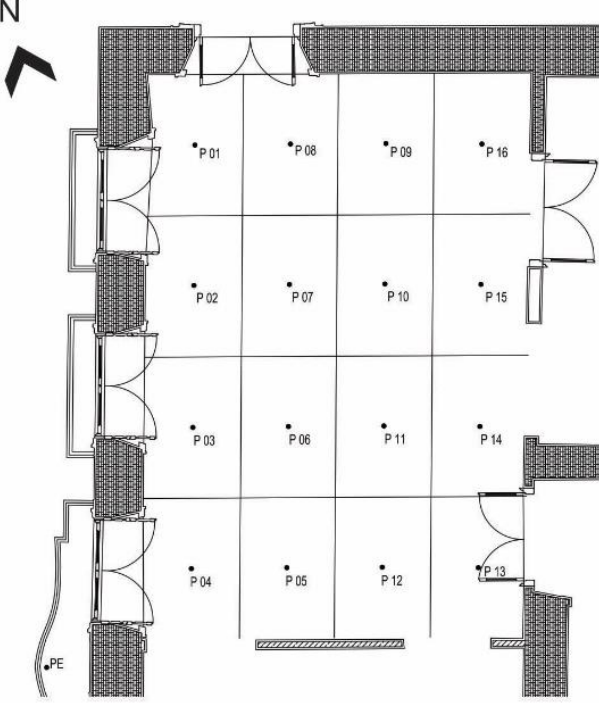

AMBIENTE 1 Norte e Oeste

Fonte: Adaptação de PELOTAS (2002)

\subsection{Aplicação de questionários}

Questionários foram aplicados, simultaneamente ao período de medições com aparelhos, com os usuários dos ambientes escolhidos no período de medição das 15:00 horas. Esse horário foi escolhido por apresentar o maior número de funcionários nos ambientes, além de ser um período em que os mesmos já se encontram aclimatados ao local.

Ao todo, 7 funcionários trabalham entre os períodos da manhã e tarde nos ambientes selecionados. Durante a aplicação dos questionários, 6 funcionários estavam no local e responderam aos questionários, representando 85\% da população. Optou-se por entrevistar apenas funcionários, visto que a aceitação e expectativa do usuário é diferente para cada uso de ambiente (INTERNATIONAL ENERGY AGENCY, 2000). Ou seja, o usuário que trabalha durante um longo período não terá a mesma percepção em relação à qualidade da iluminação, que um usuário que frequentou o mesmo ambiente por apenas alguns minutos, apenas para ser atendido.
Os mesmos questionários foram aplicados duas vezes, sendo uma vez para o período com utilização da iluminação natural e outra para o período com iluminação natural e artificial. Dessa forma, um total de 12 questionários foram preenchidos.

\section{Resultados e Discussão}

Além do levantamento das características físicas dos ambientes analisados, que interferem na resposta aos objetivos do trabalho, foram apresentados os resultados para as medições lumínicas e para a percepção dos usuários. Em seguida, os dois resultados foram confrontados.

\subsection{Levantamento dos ambientes}

Os dois ambientes contam com portas-janelas com acesso a balcões e terraços. Apenas o ambiente 2 conta também com duas janelas convencionais. As características das aberturas voltadas ao exterior foram levantadas, por serem os elementos que garantem a iluminação natural no interior dos ambientes, visível na Figura 4 e Tabela 1 . 
Figura 4: Representação das esquadrias existentes nos ambientes

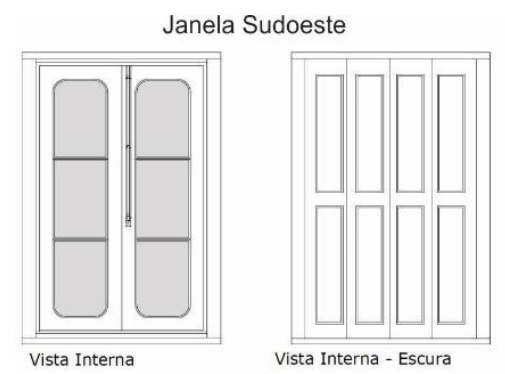

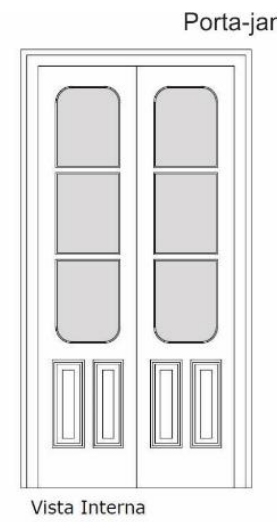

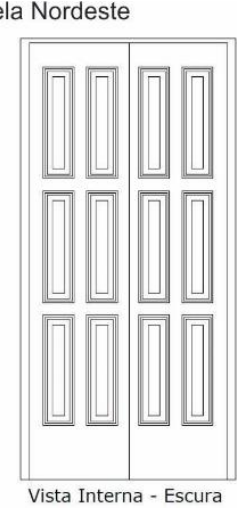

Vista Interna - Escura

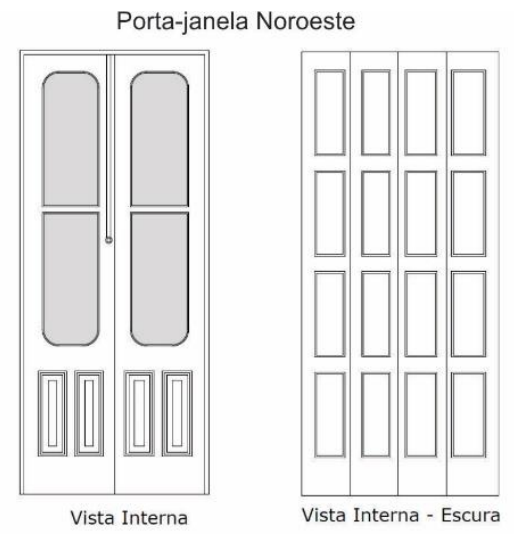

Fonte: Adaptação de PELOTAS (2002)

Tabela 1: Características físicas das aberturas para o meio externo nos ambientes em estudo

\begin{tabular}{|c|c|c|c|c|}
\hline Ambiente & Dimensões $(1 \mathrm{x} \mathrm{h} / \mathrm{p})$ & Orientação Solar & Área de vidro $\left(\mathrm{m}^{2}\right)$ & $\begin{array}{c}\text { Relação área do } \\
\text { piso/ da janela }\end{array}$ \\
\hline 1 & $1,15 \mathrm{~m} \times 2,70 \mathrm{~m}$ & 3 unid. Noroeste & 4,24 & $35 \%$ \\
\hline $\mathbf{2}$ & $1,40 \mathrm{~m} 2,70 \mathrm{~m}$ & 1 unid. Nordeste & & $36 \%$ \\
\hline & $1,15 \mathrm{~m} \times 2,70 \mathrm{~m}$ & 3 unid. Noroeste & 5,32 & \\
\hline
\end{tabular}

Fonte: Adaptação de RITTER (2014)

As janelas são verticais e distantes por intervalos que garantem a simetria da fachada. Tal característica é típica do método construtivo da época, onde as soluções estruturais eram simples (PHILIPS, 2004).

Todos os elementos de iluminação natural possuem postigos internos de madeira, que permitem que a luz externa seja barrada. Os postigos são bastante utilizados pelos usuários, permanecendo fechados durante muitas horas, a fim de impedir ofuscamento e reflexos. $\mathrm{O}$ ambiente 2 possui maior área de vidros, que permitem a iluminação natural, quando comparado ao ambiente 1 , talvez como medida de compensação do próprio projeto por ter orientação voltada ao Sul. Os ambientes possuem pouca diferença na relação área de piso e área de janelas. Ambos possuem mais do que os vãos mínimos para iluminação natural estipulados pelo Código de Obras de Pelotas para ambientes de permanência prolongada.
O ambiente 1, conforme Figura 5, conta com dois pontos de iluminação artificial no forro. Em cada um dos pontos existe duas lâmpadas fluorescentes tubulares de cor branca. No entanto, apenas três lâmpadas funcionam. Segundo Gugliermetti e Bisegna (2009), essa tipologia de lâmpada oferece baixo custo de utilização, possibilidade de escolha de temperatura de cor e longa duração. No entanto, é sensível à temperatura do ambiente e apresenta limitação do controle de qualidade ótico.

No ambiente 2, Figura 5, também existem dois pontos de iluminação artificial no forro. Em cada ponto existem quatro refletores com lâmpadas halógenas na cor amarela. Contudo, apenas seis lâmpadas funcionam. As lâmpadas halógenas apresentam grande duração e pequena dimensão, no entanto, como maior desvantagem está o alto desenvolvimento de calor (GUGLIERMETTI; BISEGNA, 2009). 
Figura 5: Layout dos ambientes e localização dos pontos de iluminação artificial no forro
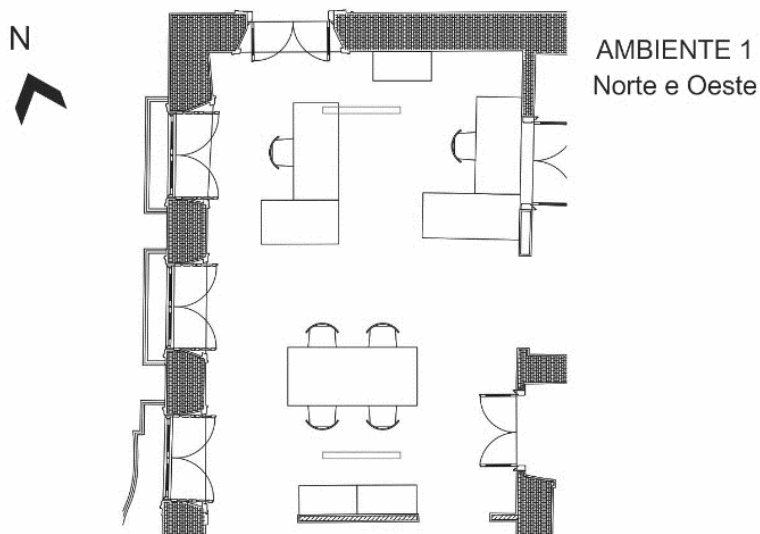

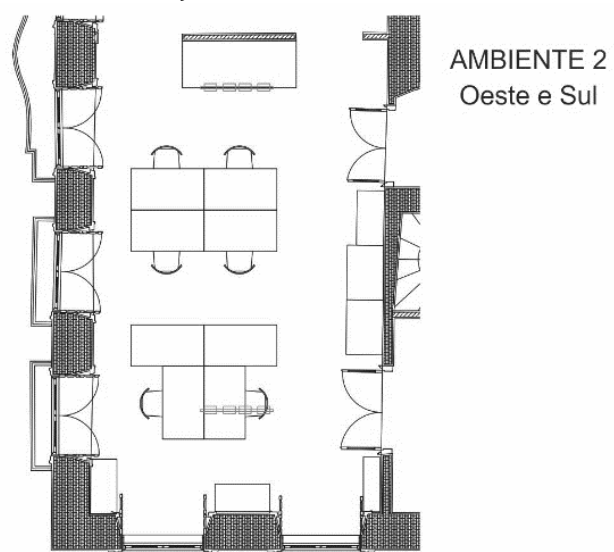

Fonte: adaptação de PELOTAS (2002)

A escolha de tipo de lâmpada é equivocada no ambiente 2, pelo fato de gerar calor e ser muito mais usual em ambientes de exposição. Já a quantidade e disposição dos pontos de iluminação superficial se mostram ineficientes, em ambos ambientes, para o uso de atividades de escritório, que envolvem leitura e escrita.

Além disso, o sistema de iluminação artificial não foi projetado pensando no aproveitamento da iluminação natural. Uma possível alternativa para melhor aproveitamento da luz solar é trabalhar com a iluminação artificial em sistemas separados, que possam ser acionados de acordo com o distanciamento das janelas. Isso maximiza o potencial de iluminação natural e gera economia de energia (GUGLIERMETTI; BISEGNA, 2009).

A disposição dos móveis utilizados pelos funcionários mostra-se bastante improvisada. O ambiente 1 apresenta menos elementos móveis que o ambiente 2, sendo o último com maiores problemas de espaço para passagem e atendimento ao público. Essa disposição sem relação com a localização das aberturas e pontos de iluminação artificial, pode ser a causa para ofuscamentos e saturações de cor nas telas dos computadores, o que leva os usuários a fecharem os postigos.

\subsection{Resultados das medições lumínicas}

A fim de analisar os níveis de Contribuição de Iluminação Natural (CIN) no interior dos ambientes, foram realizadas medições em um ponto externo à edificação nos cinco horários avaliados, além de imagens das condições de céu. No dia do levantamento o céu estava claro durante as três primeiras medições, tornando-se encoberto nas duas últimas, conforme Figura 6.

Figura 6: Condições de céu no momento das medições

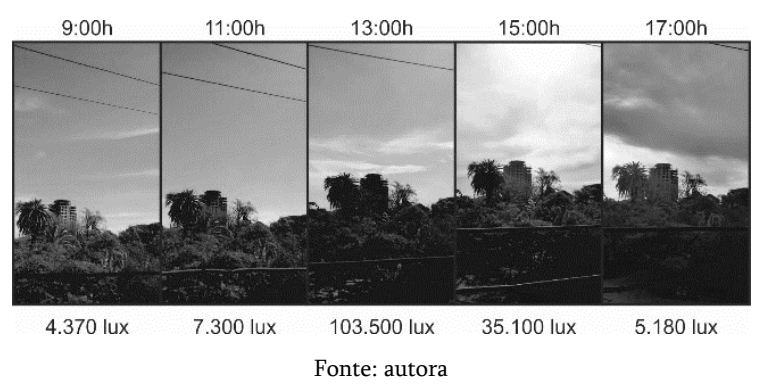

A fim de facilitar a visualização dos pontos com maior e menor intensidade de iluminância foram confeccionados esquemas gráficos a partir de uma escala de cores, a Figura 7 mostra um exemplo. A escala de cores foi elaborada com base nas classificações de Contribuição de Iluminação Natural internacionais utilizadas em Ritter (2014), sendo ela: CIN muito baixo, abaixo de $1 \%$; CIN baixo, de 1 a 2\%; CIN moderado, de 2 a $4 \%$; CIN médio, de 4 a $7 \%$; CIN elevado, de 7 a $12 \%$; e CIN muito elevado, acima de $12 \%$. Os esquemas foram elaborados levando em consideração o CIN de cada ponto dos ambientes 1 e 2, nos horários das 9h, 11h, 13h, 15h e 17 horas, para o caso de utilização da iluminação natural e de utilização da iluminação natural e artificial, o que permitiu maior clareza no momento de análise dos resultados. 
Figura 7: Exemplo de esquema gráfico para interpretação visual das medições
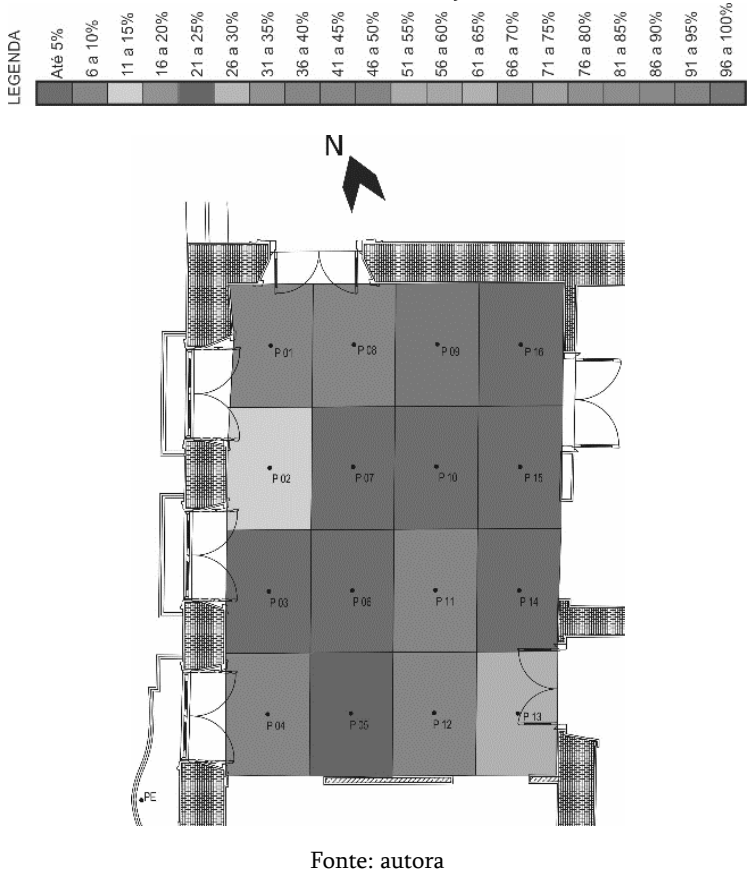

É importante ressaltar que, durante a manhã, os dois ambientes estavam com todos os postigos abertos. A partir da medição das 13:00 horas os postigos começaram a ser fechados, sendo que ao final do dia existia uma janela com postigo fechado no ambiente 1 e duas janelas com postigos fechados no ambiente 2 .

O ambiente 1 apresentou apenas $20 \%$ dos pontos avaliados, quando da utilização apenas da luz natural, com CIN igual ou maior que $6 \%$. Isso indica que, em grande parte dos pontos, o CIN apresenta-se abaixo de médio. Essa porcentagem aumentou quando a iluminação artificial foi considerada, passando para $26,25 \%$ dos pontos. No entanto, esse valor ainda é muito baixo, considerando a porcentagem de aberturas em relação à área da sala.

O ambiente 2, por sua vez, apresentou uma porcentagem de $21,25 \%$ de pontos com CIN igual ou maior que $6 \%$, quando considerada apenas a iluminação natural, e 31,25\% quando a iluminação artificial foi considerada. Isso indica uma influência maior da iluminação artificial nas condições de iluminação do ambiente 2, quando comparado ao ambiente 1. Entretanto, os valores ainda são muito baixos, alcançando o CIN médio em poucos pontos durante todas as medições. Esse fato pode ser comparado com o estudo de Bustamante et al (2012), que identificou serem os meses de verão, e das estações intermediárias, os mais críticos no quesito de conforto lumínico. Isto para edifícios de escritório com uso intensivo durante o dia, como é o caso dos ambientes em estudo.

De acordo com a NBR 8995-1 (ABNT, 2013), escritórios necessitam atender a valores de iluminância mantida de, no mínimo, 500 lux. Sendo assim, realizou-se também a análise de adequação aos valores normatizados nos dois ambientes, para as duas formas de utilização da iluminação: apenas natural e iluminação natural e artificial. Essa análise foi realizada a fim de confirmar a avaliação por CIN.

A partir da Tabela 2, é possível confirmar os resultados obtidos na primeira análise das medições. Os dois ambientes atingem os níveis estipulados de iluminância em poucos momentos durante o dia. Em um trabalho realizado por Aykal et al (2011), onde é feita a análise de conforto lumínico em um prédio histórico que passou por retrofit, os valores medidos por luxímetros também não satisfizeram as condições necessárias para o uso de escritório. Demonstrando a importância de uma maior atenção às necessidade relacionadas ao novo uso de edificações históricas.

A utilização dos ambientes com postigos fechados, devido à necessidade de melhorar o conforto visual por parte dos usuários, bem como o layout dos móveis, podem ter contribuído para a não observância dos valores mínimos. Porém, quando a iluminação artificial foi considerada, os valores não tiveram grande alteração, demonstrando que os pontos de iluminação artificial também são insuficientes às atividades realizadas nos ambientes. 
Tabela 2: Porcentagem de valores iguais ou maiores a 500lux em todas as medições

\begin{tabular}{|c|c|c|}
\hline Ambiente & Somente iluminação natural & Iluminação natura/ artificial \\
\hline 1 & $22,5 \%$ & $30 \%$ \\
\hline 2 & $23,75 \%$ & $23,75 \%$ \\
\hline
\end{tabular}

Fonte: autora

\subsection{Resultados da percepção dos usuários}

A fim de analisar as respostas dos questionários aplicados aos funcionários, as porcentagens totais foram consideradas em relação à cada ambiente e não considerando os dois juntos. Ou seja, 100\% de respostas em relação ao ambiente 1 e $100 \%$ de respostas em relação ao ambiente 2 , como mostra a Tabela 3.

Tabela 3: Porcentagens das respostas aos questionários

\begin{tabular}{|c|c|c|c|c|}
\hline \multirow{2}{*}{ Questões } & \multicolumn{2}{|c|}{ Iluminação Natural } & \multicolumn{2}{|c|}{ Ilum. Natural e Artificial } \\
\hline & Ambiente 1 & Ambiente 2 & Ambiente 1 & Ambiente 2 \\
\hline $\begin{array}{l}\text { 1. Como você descreveria a } \\
\text { iluminação em seu local de } \\
\text { trabalho? }\end{array}$ & $\begin{array}{l}\text { Clara: } 50 \% \\
\text { Confortável: 50\% }\end{array}$ & $\begin{array}{l}\text { Confortável: } 25 \% \\
\text { Escura: } 75 \%\end{array}$ & Confortável: $100 \%$ & $\begin{array}{l}\text { Confortável: 25\% } \\
\text { Escura: } 75 \%\end{array}$ \\
\hline $\begin{array}{l}\text { 2. Como você gostaria que } \\
\text { a iluminação estivesse } \\
\text { nesse momento? }\end{array}$ & $\begin{array}{l}\text { Muito mais clara: } \\
50 \% \\
\text { Mais clara: } 50 \%\end{array}$ & Mais clara: $100 \%$ & $\begin{array}{l}\text { Mais clara: } 50 \% \\
\text { Nem mais clara, } \\
\text { nem mais escura: } \\
50 \%\end{array}$ & $\begin{array}{l}\text { Mais clara: } 75 \% \\
\text { Nem mais clara, } \\
\text { nem mais escura: } \\
25 \%\end{array}$ \\
\hline $\begin{array}{l}\text { 3. Nesse momento, você } \\
\text { considera necessário o uso } \\
\text { de iluminação artificial? }\end{array}$ & Sim: $100 \%$ & Sim: $100 \%$ & $\begin{array}{l}\text { Sim: } 50 \% \\
\text { Não: } 50 \%\end{array}$ & $\begin{array}{l}\text { Sim: } 75 \% \\
\text { Não: } 75 \%\end{array}$ \\
\hline $\begin{array}{l}\text { 4. Nesse momento, você } \\
\text { prefere as janelas: }\end{array}$ & Abertas: $100 \%$ & Abertas: $100 \%$ & Abertas: $100 \%$ & Abertas: $100 \%$ \\
\hline $\begin{array}{l}\text { 5. Você gostaria de utilizar } \\
\text { algum método de } \\
\text { aquecimento ou } \\
\text { resfriamento nesse } \\
\text { momento? }\end{array}$ & Não: $100 \%$ & Não: $100 \%$ & Não: 100\% & Não: 100\% \\
\hline $\begin{array}{l}\text { 6. Você precisa realizar } \\
\text { algum tipo de esforço } \\
\text { visual para executar suas } \\
\text { atividade? }\end{array}$ & $\begin{array}{l}\text { Sim: } 50 \% \\
\text { Não: } 50 \%\end{array}$ & $\begin{array}{l}\text { Sim: } 75 \% \\
\text { Não: } 25 \%\end{array}$ & $\begin{array}{l}\text { Sim: } 50 \% \\
\text { Não: } 50 \%\end{array}$ & $\begin{array}{l}\text { Sim: } 50 \% \\
\text { Não: } 50 \%\end{array}$ \\
\hline $\begin{array}{l}\text { 7. Levando em conta as } \\
\text { questões anteriores, você } \\
\text { considera a sala, nesse } \\
\text { momento, em relação à } \\
\text { iluminação: }\end{array}$ & $\begin{array}{l}\text { Desconfortável: } \\
100 \%\end{array}$ & $\begin{array}{l}\text { Desconfortável: } \\
100 \%\end{array}$ & $\begin{array}{l}\text { Confortável: } 50 \% \\
\text { Desconfortável: } \\
50 \%\end{array}$ & $\begin{array}{l}\text { Desconfortável: } \\
50 \%\end{array}$ \\
\hline
\end{tabular}

Fonte: autora

A partir das respostas é possível perceber que a maioria dos usuários gostaria que os ambientes fossem mais claros. Também foi verificado que todos os usuários preferem as janelas abertas.
Juntando esse dado ao fato de que uma porcentagem significativa respondeu que precisa realizar algum tipo de esforço para realizar as atividades, é possível compreender que os postigos 
são fechados para evitar ofuscamentos, e não pelo fato de a sala não necessitar de maior iluminação.

Segundo a International Energy Agency (2000), efeitos de iluminação natural são esperados quando utilizados sistemas convencionais de janelas, como ofuscamentos e saturações. No entanto, o grau de aceitação por parte dos usuários dependerá sempre do uso ao qual é destinado o ambiente.

O fato de $100 \%$ dos usuários responder que não considera necessário o uso de algum método de resfriamento ou aquecimento, no momento dos questionários, também confirma a hipótese citada acima, de que os postigos somente são fechados para evitar reflexos na área de trabalho.

A maior parte dos usuários, nos dois momentos das medições, considera necessário o uso de iluminação artificial no ambiente de trabalho. Isso demonstra a iluminação precária para realização de atividades relacionadas a escritórios.

Comparando as respostas dos dois ambientes, é possível afirmar que os usuários do ambiente 2 consideram seu local de trabalho mais escuro que os usuários do ambiente 1. No entanto, em ambos ambientes, os usuários consideraram desconfortável seus locais de trabalho, quanto à iluminação, após terem respondido às seis primeiras perguntas do questionário. Isso porque as questões anteriores fizeram com que os mesmos refletissem mais a fundo à respeito das condições de iluminação.

\subsection{Comparação entre as medições lumínicas e a percepção dos usuários}

As respostas dos usuários confirmam as medições das condições lumínicas realizadas nos ambientes. No ambiente 1 as condições consideradas aceitáveis, em relação à iluminância, foram alcançadas em apenas $22,5 \%$ de todos os pontos medidos quando utilizada apenas iluminação natural. Para essa mesma condição, os usuários consideraram necessário o uso da iluminação artificial e gostariam que a sala fosse mais clara. Quando a iluminação artificial foi ligada, os níveis considerados aceitáveis para as atividades foram alcançados em $30 \%$ dos pontos. Para essa mesma condição, os usuários consideraram a sala confortável, ou seja, sem necessidade de tornar-se mais clara nem mais escura.

O ambiente 2 apresentou a mesma porcentagem de condições consideradas aceitáveis nas duas condições de medição, 23,75\%. Na primeira condição $100 \%$ dos usuários gostaria que a sala fosse mais clara e consideraram necessário o uso da iluminação artificial. Na segunda condição, com a iluminação artificial ligada, a porcentagem de usuários passou para $75 \%$ nas mesmas respostas. $\mathrm{O}$ que demonstra que a maior parte deles continuou considerando a sala mal iluminada.

\section{Conclusões}

A partir dos resultados é possível afirmar que, para este caso, o processo de retrofit visou a manutenção das características formais da edificação, porém, não contemplou os aspectos de conforto lumínico dos usuários. As janelas, apesar de satisfazerem as regras no Código de Obras da cidade de Pelotas, não promovem uma iluminação eficiente em todos os pontos da sala. Por promoverem pontos de ofuscamento, a medida utilizada é fechar os postigos, que barram completamente a incidência de luz natural, apresentando-se não condizentes para o uso dos ambientes.

Os pontos de iluminação artificial também não mostram-se eficientes e nem mesmo apropriados para as atividades realizadas nos cômodos. $\mathrm{O}$ fato de o layout dos ambientes analisados apresentar-se improvisado, também confirma a conclusão, demonstrando que não foi realizado um projeto nem mesmo para a disposição das estações de trabalho.

Sendo assim, conclui-se que o processo de retrofit não atingiu todos os seus objetivos no caso dos dois ambientes do Casarão 2 da cidade de Pelotas, visto que os usuários dos destes não se sentem confortáveis com relação às condições lumínicas. Além disso, as questões de percepção dos usuários foram confirmadas através das medições das condições de iluminação nos ambientes, que se mostraram ineficientes. 


\section{Referências}

\section{ASSOCIAÇÃO BRASILEIRA DE NORMAS} TÉCNICAS. NBR 8995. Iluminação de ambientes de trabalho - Parte 1: Interior. Rio de Janeiro, 2013.

NBR 15215. Iluminação natural - Parte 4: Verificação experimental das condições de iluminação interna de edificações - Método de medição. Rio de Janeiro, 2005.

AYKAL, D.; GÜMÜS, B.; ÜNVER, R.; MURT, O. An approach to evaluation of re-functioned historical buildings in view of natural lighting, a case study in Diyarbakir Turkey. In: Light and Engineering. v. 19. n. 2. p. 64-76. 2011.

BUSTAMANTE, W.; BUSTAMANTE, F.E; OTÁROLA, R.; PINO, A. Análisis de estratégias para confort térmico y lumínico de edificios em diferentes climas de la zona central del Chile. In: ARQ. n 82. p. 112-115. 2012.

CHOAY, F. A alegoria do patrimônio. São Paulo: UNESP, 2001.

GONÇALVES, J.C.S.; VIANNA, N.S.; MOURA, N.C.S. Iluminação natural e artificial. Rio de Janeiro: ELETROBRAS PROCEL, 2011.

GUERRA, S. O uso do patrimônio histórico (o caso do Paço Imperial). In: Cadernos PROARQ. ed. 10. p. 115 - 118. 2006.

GUGLIERMETTI, F.; BISEGNA, F. Integrazione luce naturale/ luce artificiale in âmbito industriale Parte 2: Analisi delle possibili tecniche, componenti e regolazioni per l'illuminazione artificiale/ naturale. Roma, 2009.

HEIDTMANN, D.E.D. Novos usos para edificações de interesse histórico e cultural: lições da produção arquitetônica pelotense. 2007. Dissertação (Mestrado em Planejamento Urbano) - Programa de Pós-Graduação em Arquitetura e Urbanismo, Universidade Federal de Santa Catarina.

INTERNATIONAL ENERGY AGENCY. Daylight in buildings. A source book on daylighting systems and components. IEA SHS Task 21 - ECBCS Annex 29, 2000. 262p.

KNOP, S. Comportamento termoenergético de edificação histórica com novo uso na cidade de Pelotas: o caso do casarão 02 - Secretaria Municipal da Cultura. 2012. Dissertação (Mestrado em Arquitetura e Urbanismo) - Programa de PósGraduação em Arquitetura e Urbanismo, Universidade Federal de Pelotas.

MEIRA, A.L.G. O patrimônio histórico e artístico nacional no Rio Grande do Sul no século $\mathrm{XX}$ : atribuição de valores e critérios de intervenção. 2008. Tese (Doutorado em Planejamento Urbano Regional) - Programa de Pós-Graduação em Planejamento Urbano e Regional, Universidade Federal do Rio Grande do Sul.

PELOTAS. Prefeitura Municipal de Pelotas, Secretaria Municipal de Cultura. Programa de Recuperação do Centro Histórico de Pelotas. Projeto de Restauração da Casa 2. Plantas diversas. Pelotas, 2002.

PHILLIPS, D. Daylighting. Natural light in architecture. Architectural Press, Elsevier: 2004. 227p.

RABELLO, S. O Estado na preservação de bens culturais: o tombamento. Rio de Janeiro: IPHAN, 2009.

RHEINGANTZ, P.A.; AZEVEDO, G.A; BRASILEIRO, A.; ALCANTARA, D.; QUEIROZ, M. Observando a qualidade do lugar: procedimentos para avaliação pós-ocupação. Rio de Janeiro: PROARQ, 2009

RITTER, V. M. Avaliação das condições de conforto térmico, lumínico e acústico no ambiente escolar, no período de inverno: $\mathrm{O}$ caso do câmpus Pelotas Visconde da Graça. 2014. Dissertação (Mestrado em Arquitetura e Urbanismo) - Programa de PósGraduação em Arquitetura e Urbanismo, Universidade Federal de Pelotas.

SECRETARIA MUNICIPAL DE CULTURA. Manual do usuário de imóveis inventariados. 1.ed. Pelotas: Nova Prova, 2008. 104p. 